\title{
Advanced Graphical-Analytical Method of Pipe Tank Design Integrated with Sensitivity Analysis for Sustainable Stormwater Management in Urbanized Catchments
}

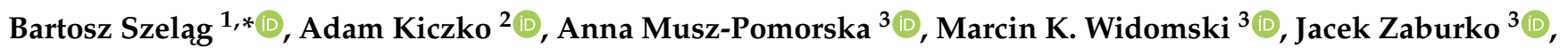 \\ Grzegorz Łagód ${ }^{3, *(D)}$, David Stránský ${ }^{4}$ (D) and Marek Sokáč ${ }^{5}$ (D) \\ 1 Faculty of Environmental, Geomatic and Energy Engineering, Kielce University of Technology, \\ 25-314 Kielce, Poland \\ 2 Faculty of Civil and Environmental Engineering, Warsaw University of Life Sciences-SGGW, \\ 02-797 Warsaw, Poland; adam_kiczko@sggw.pl \\ 3 Faculty of Environmental Engineering, Lublin University of Technology, 20-618 Lublin, Poland; \\ a.musz-pomorska@pollub.pl (A.M.-P.); m.widomski@pollub.pl (M.K.W.); j.zaburko@pollub.pl (J.Z.) \\ 4 Faculty of Civil Engineering, Czech Technical University in Prague, 16629 Prague 6, Czech Republic; \\ david.stransky@cvut.cz \\ 5 Institute of Hydrology, Slovak Academy of Sciences, 84104 Bratislava, Slovakia; sokac@uh.savba.sk \\ * Correspondence: bszelag@tu.kielce.pl (B.S.); g.lagod@pollub.pl (G.Ł.); Tel.: +48-41-34-34-73 (B.S.); \\ $+48-81-538-4322$ (G.E.)
}

check for updates

Citation: Szelag, B.; Kiczko, A.; Musz-Pomorska, A.; Widomski, M.K.; Zaburko, J.; Łagód, G.; Stránský, D.; Sokáč, M. Advanced

Graphical-Analytical Method of Pipe Tank Design Integrated with Sensitivity Analysis for Sustainable Stormwater Management in Urbanized Catchments. Water 2021, 13, 1035. https://doi.org/10.3390/ w13081035

Received: 22 January 2021

Accepted: 6 April 2021

Published: 9 April 2021

Publisher's Note: MDPI stays neutral with regard to jurisdictional claims in published maps and institutional affiliations.

Copyright: (c) 2021 by the authors. Licensee MDPI, Basel, Switzerland. This article is an open access article distributed under the terms and conditions of the Creative Commons Attribution (CC BY) license (https:/ / creativecommons.org/licenses/by/ $4.0 /)$.

\begin{abstract}
Pipe tanks represent important runoff retention elements of urban stormwater systems. They enable us to reduce and retain runoff as well as to mitigate peak flows in the network. Pipe tanks are often taken into account while designing the spatial plan of urban catchment areas. Hence, there is a need to develop a relatively quick and accurate method for pipe tank dimensioning. A graphical-analytical method of designing a pipe tank is presented in the paper. In the assumed methodology, the possibility of employing machine learning for obtaining a more precise error prediction of the proposed pipe tank design method (compared with the tank volume simulations using the storm water management model (SWMM)) are considered. Thus far, this aspect has not been discussed in the literature. In the adopted calculation methodology, sensitivity analysis constitutes an important element, enabling us to assess the influence of the input data assumed for tank design on the dimensions of the outflow devices and the length of the retention chamber.
\end{abstract}

Keywords: sustainable stormwater management; urban stormwater systems; local area retention; pipe tank; low-impact development (LID); machine learning; storm water management model (SWMM)

\section{Introduction}

The sustainable development of urbanized areas [1,2] should be understood as growth based on the proper usage of natural resources, including water [3-5], which is commonly endangered by urbanization itself [6,7], population growth, and climate change $[4,8]$. Climate change may be mainly related to floods, droughts, heatwaves, and other threats to human comfort and urban environments caused by increased numbers of rapid and extreme weather events $[9,10]$.

The volume of available water resources may be significantly reduced by anthropogenic pressure caused by water usage by residents, services, and industry. The improper handling of sanitary sewage, combined with increased urbanization, may also affect the availability of water. Thus, the protection and sustainable management of water resources to prevent water shortages are crucial to the sustainable development of urbanized regions.

The increase in the degree of urbanized catchments, related to the construction of living and public buildings, services, roads, pavements, and parking lots, clearly affects the natural water balance of catchment [10-12]. 
Urbanization changes catchment hydrology and leads to the generation of high-peak runoff flows in a relatively short time. On the other hand, in a natural catchment, a significant part of rainwater infiltrates the soil, recharges the groundwater, and is absorbed or transpired by plants [7]. In the case of an urbanized catchment with a range of 70-100\% of the surface area being sealed, the surface runoff may reach 55\% of rainfall depth, while evapotranspiration and infiltration may reach $30 \%$ and $15 \%$ of the surface water, respectively [13]. By contrast, in natural catchments evapotranspiration reaches $40 \%$, while infiltration supplies the groundwater to approx. 50\% of the rainfall depth. Surface runoff in natural catchments is significantly lower and reaches a level of only $10 \%$ of the precipitation $[9,14]$.

However, the development or construction of new or existing centralized stormwater systems for urbanized areas, as a typical and standard reaction to urban development should no longer be treated as feasible $[11,12,15]$. Thus, an effective source control solution is required to significantly reduce runoff, urban flooding risks, and pollutant discharge to surface water [16]. The development of urbanized areas is being increasingly supported by low-impact development (LID) urbanistic planning techniques [17-21], whose main purpose is urban flooding management through the control of stormwater outflow and weakening of peak runoff flows [22-24]. These additional advantages are possible due to the use of numerical modeling applications in LID optimization. Studies have shown that the application of the storm water management model (SWMM) model combined with the genetic algorithm (GA) allows for an increase in LID efficiency and a reduction of application costs [25]. Sustainable stormwater management systems [12,20,21], the alternative to the traditional stormwater removal, reduce surface runoff and limit flow peaks and flooding by increasing interception, evapotranspiration, and infiltration $[15,16]$. These gains are possible by using plants (green architecture, green roofs [26]), the retention capabilities of porous materials (green roof fillings), permeable passageway surfaces [27,28], or over-ground and underground water reservoirs [29]. The methods of stormwater management oriented towards increased infiltration of stormwater into the soil utilize classic pavement materials with gaps or materials pervious to water, allowing for a reduction of the runoff volume and an increase in the infiltration ratio [15,27,30-32]. Additionally, LID applications bring environmental benefits, including improvements in water quality, a decrease in air pollution [33-35], and an increase in biodiversity. Green infrastructure is capable of significantly reducing the volume of surface runoff from $50 \%$ to $100 \%$, in relation to the catchment characteristics and local precipitation $[9,27,36]$. The model studied by the LID module confirmed the influence of LID (infiltration ditches, permeable surfaces, and green roofs) on surface runoff reduction $[37,38]$. The presented methods of stormwater management also result in an improvement of the water quality due to the usage of biogens by plants and pollutant adsorption on the surface of the solid phase particles of porous media $[9,27,38]$. The reduction in the total phosphorus (TP) and total suspended solids(TSS) volumes by green infrastructure was reported to be at a range of $65-100 \%$ [9]. There are also reported social and economic advantages to LID [39-41]. The application of damming baffles in stormwater systems is an exemplary implementation of LID to urban water management. Studies by Starzec and Dziopak [42] showed an increase in retention capacity and a decrease in determined peak flow by $60 \%$, in comparison to traditional stormwater removal systems. In order to determine the efficiency of various LID systems, the control of the volumetric outflow of water is required, i.e., by the application of a flow meter with a wide flow velocity range [43].

The reduction of the drinking water demand in residential areas and the decrease in anthropogenic pressure exerted on surface waters by untreated stormwater is possible due to the application of various rainwater harvesting ( $\mathrm{RWH})$ systems [44-50]. RWH, as a method of interception and storage of rainwater, allows us to obtain non-potable water for domestic purposes, including toilets, laundry, and gardening, reducing the drinking water demand by $60-80 \%$ [44,51-54]. Harvested water can be stored in different types of tanks. Studies based on tanks introduced to existing stormwater systems combined with 
their real-time operational monitoring indicated that in relation to the location and volume of the tank, a reduction of runoff volume by $18-40 \%$ was possible [55]. The application of optimization techniques results in more effective reuse of acquired rainwater and a decrease in the surface runoff volume, which is important for smart city planning and development [56,57]. Real-time control techniques can also help in decreasing the flows discharged from quality-oriented combined sewer overflow devices [58].

Retention tanks represent important objects in municipal sewerage networks [59-63]. The distinct shape of the retention chamber enables us to employ any configuration of outlet devices, which allows us to achieve a constant outflow rate from the tank. Thus far, a similar effect has been achieved in multi-chamber tanks, with a rectangular cross-section of the retention chamber. Despite similar hydraulic efficiency, the placement and manufacturing of a pipe tank are much easier than in the case of a classic rectangular tank, since it can be located more easily, and its interference with the existing network of the underground infrastructure is lower. The currently employed methods of tank dimensioning are largely based on hydrodynamic modeling. Due to the complexity of the modeled phenomena, issues with the continuity of the calculation algorithm can occur. Examples involving the application of hydrodynamic models for the dimensioning of pipe tanks were presented by Kisiel et al. [64] and Mrowiec [60,65]. Graphical methods connected with the numerical solving of differential equations are quite popular, since they permit relatively quick calculation of the tank volume, while also being highly precise. However, other methods were also developed, in which a hydrograph of the tank outflow was schematized using a triangle, rectangle, or trapezium shape [59,66-68]. In turn, a simplified model with a graphical-analytical method was proposed by Szelag and Kiczko [69]. However, the obtained results exhibited the limited applicability of the proposed calculation method.

The aim of this paper is to present an advanced graphical-analytical method for pipe tank design, integrated with a comprehensive sensitivity and error dependency analysis. Such a dimensioning method can be used as a complement and support tool in combination with the currently used hydrodynamic models. The assessment of the influence of the inflow hydrograph parameters and the outlet device characteristics on the designed tank volume is important from the point of view of selecting the input parameters for its dimensioning, in order to meet the required overflow and flooding criteria (e.g., overflow and flooding occurrence/periodicity, number of storm overflows per year, and flooding return time). The application of an artificial intelligence method enables us to investigate the influence of the interactions between the hydrograph parameters and the characteristics of outlet devices on the results of the volume calculations, and thus allows us to propose a methodology for reducing these interactions, which is the main novelty of this paper. This objective fits within the issue of sustainable urban stormwater management systems by enhancing the possibility of local retention, enabling the use of the accumulated stormwater (in case of separate storm sewer systems without the presence of sanitary wastewater, which is a common situation in Poland) as well as mitigating local flood occurrences due to the hydraulic surcharge and decrease of the CSOs (combined sewer overflows) of the sewerage system.

\section{Materials and Methods}

\subsection{Calculation Algorithm Concept}

A novel modification of the graphical-analytical method of retention tank design (dimensioning) by introducing an advanced sensitivity analysis and modeling error was proposed. The presented approach constitutes an extension of the previously employed graphical-analytical tank dimensioning methods with the algorithms enabling us to improve the accuracy of the obtained calculation results. Using the graphical and analytical method, it was possible to pre-define the length of the tank chamber and to design the overflow devices. The additional implementation of data mining methods allowed us to detail the simulation results so that they were consistent with the results of the calculations of the length of the reservoir chamber obtained by means of differential equations. Statis- 
tical models determined with the data mining methods were employed for this purpose. The steps of the proposed methodology are presented in Figure 1. Compared with the graphical-analytical methods developed thus far, the proposed methodology enabled the determining the factors affecting the errors resulting from the interpolation of the dependencies between the characteristics of the influent hydrograph and the parameters of the outlet devices and pipe tank dimensions. The sensitivity analysis, which enabled the determination of the key parameters affecting the results of the tank parameter calculations and the influence of their uncertainty on the simulation results, constitutes an important element of the presented calculation methodology.

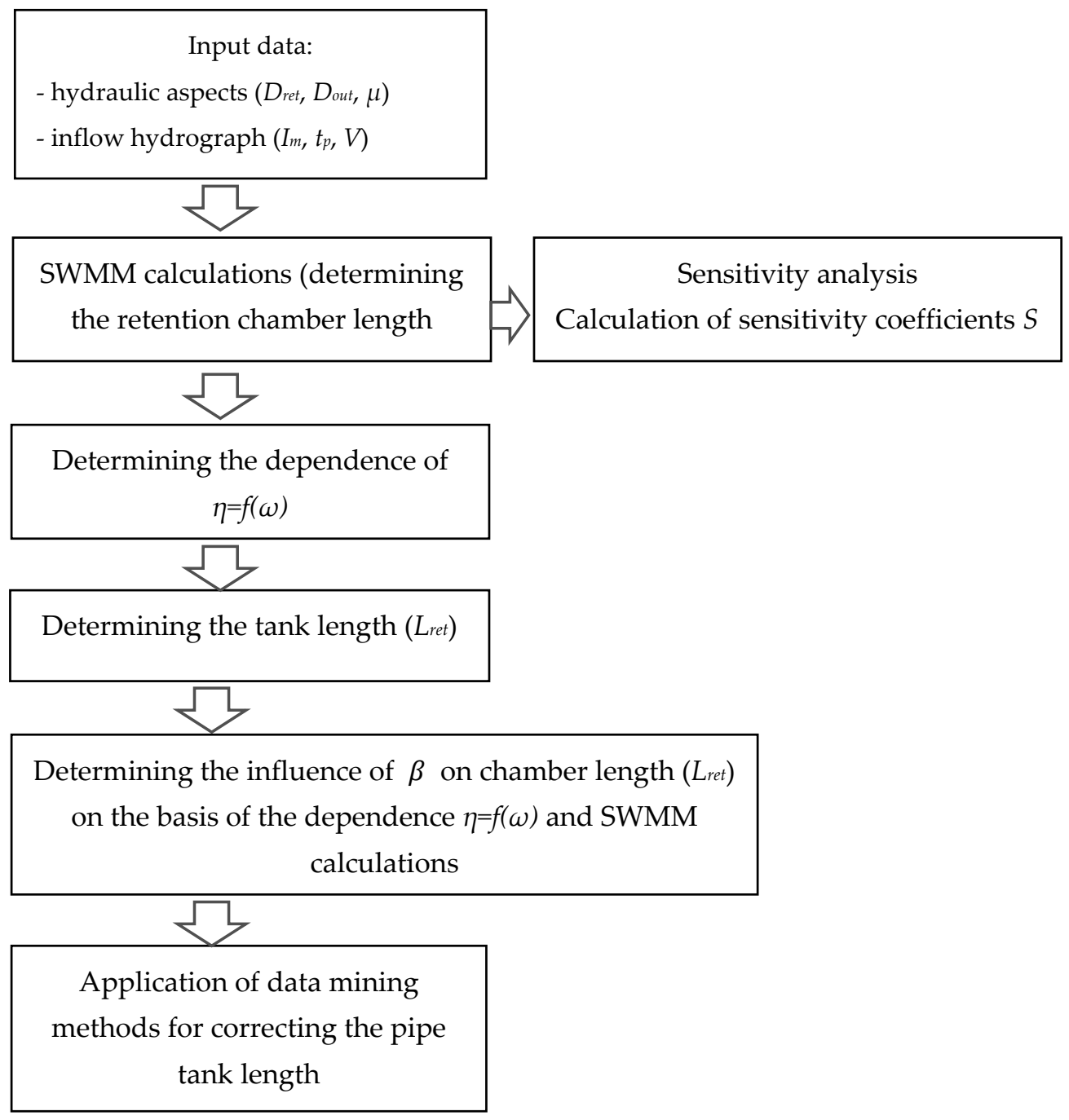

Figure 1. A schematic presentation of the algorithm for establishing the parameters of the pipe tank.

The conducted analyses involved the application of multiple linear regression models (MLR), genetic programming (GP), and artificial neural networks (ANN) as examples of data-driven algorithms [70,71]. The adopted methods were selected to determine the influence of selected independent variables on the modelled errors. In parallel, the choice was guided by the premise that efforts were made to search for the simplest data mining methods, where the determined parameters had a physical interpretation. Non-linear models were then selected to show how the linearity simplification assumption differed from the non-linear models. During the selection of the nonlinear models, the authors were guided by the fact that one of them had a physical interpretation and could be used at the stage of designing the tank by designers, and the other, i.e., the neural network model, was more sophisticated. However, there are currently many free software tools 
available that allow us to build ANN models appropriate for the described task. Out of the aforementioned data driven methods, MLR was the simplest; however, it had certain limitations. In the GP, in relation to MLR, the yielded dependence was a linear or nonlinear apparent function, and the obtained relationships had a physical interpretation. In the case of ANN, the obtained function was implicit, but due to the properties of the method it was used for simulating complex strongly non-linear dependencies [72,73]. In the neural network model, the input signals $\left(x_{i}\right)$ reaching the input layer were multiplied by the values of weights $w_{i j}$. The obtained sums were transformed using the linear or nonlinear activation function $(f)$ and then were transmitted to the neuron(s) of the output layer. The disadvantage of the neural network method was that the initial values of the weights affected the learning process, which may create problems with finding the global minimum of a function [74].

\subsection{Differential Equation of Stormwater Volume Balance}

The analyses conducted for dimensioning a pipe tank (Figure 2) involved a triangular influent hydrograph (Figure 3) [75]. By "dimensioning", we mean the design of a pipe tank storage object whose volume will ensure a reduction of the maximum runoff from the urban catchment to the required level. Several designing techniques are commonly applied during the determination of the tank dimensions. The trapezoid inflow hydrograph is accepted in cases in which a reliable rainfall depth allowing the maximal accumulative capacity is requested [76], whereas the triangular inflow hydrograph is commonly accepted in cases in which the capacity of the tank is designed to temporarily delay the outflow resulting from an excessive rainfall event $[66,77]$. According to the quoted sources and taking into account that the main purpose of the designed rainwater tank was to retain stormwater and delay its outflow, the triangular hydrograph was accepted for our analyses. The adopted assumption on the parametrization of its variability finds confirmation in the theoretical analyses conducted by many authors [68,78]. The analyses were performed for an assumed outlet in the form of a circular orifice with a diameter of $D_{o r}$. For the assumptions mentioned above, the variability in the amount of stormwater flowing into the tanks during the growth phase $\left(t_{p}\right)$ and decline phase $\left(t_{o p}\right)$ can be described with the following dependency (see also the graphical presentation in Figure 3):

$$
\begin{gathered}
I(t)=\frac{I_{m}}{t_{p}} \cdot t \text { for } 0<t \leq t_{p} \\
I(t)=I_{m} \cdot\left(1+\frac{t_{p}}{t_{o p}}-\frac{t}{t_{p}}\right) \text { for } t_{p}<t \leq t_{p}+t_{o p}
\end{gathered}
$$

where: $I(t)$ is the inflow into the tank in time $t\left(\mathrm{~m}^{3} \mathrm{~s}^{-1}\right), I_{m}$ is the peak flow to the tank $\left(\mathrm{m}^{3} \mathrm{~s}^{-1}\right), t_{p}$ is the peak flow time (min), $t_{o p}$ is the time of water lowering, and $t$ is the time (min).

By appropriately parameterizing the cross-section of the pipe tank retention chamber and assuming a triangular influent hydrograph, the following differential equation was obtained [69]:

$$
\begin{gathered}
\frac{d V}{d t}=I_{m} \cdot \frac{t}{t_{p}}-\frac{B_{o r}}{C_{z}^{0.35}} \cdot V^{0.35} \\
\frac{d V}{d t}=I_{m} \cdot\left(1+\frac{t_{p}}{t_{o p}}-\frac{t}{t_{p}}\right)-\frac{B_{o r}}{C_{z}^{0.35}} \cdot V^{0.35}
\end{gathered}
$$

where: $C_{z}$ is the geometric parameter of the tank described as $L_{r e t} \cdot D_{\text {ret }}{ }^{0.60}$ (where $L_{\text {ret }}$ is the length of the retention chamber $(\mathrm{m})$, and $D_{\text {ret }}$ is the diameter of the retention chamber $(\mathrm{m})$ ), $B_{o r}$ is the parameter describing the outlet orifice (expressed as $\mu \cdot \pi \cdot 4^{-1} \cdot D_{o u t}{ }^{2} \cdot(2 g)^{0.50}$ ), and $V$ is the tank volume variable in time $t\left(\mathrm{~m}^{3}\right)$. 


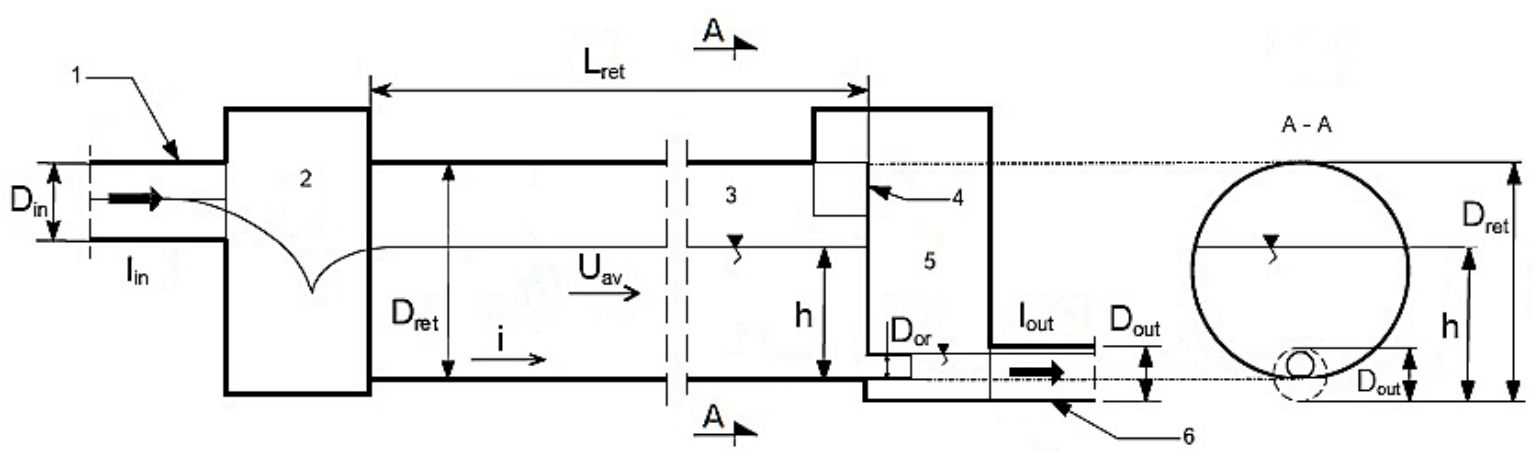

Figure 2. Scheme of a pipe tank. Where: $D_{\text {ret }}$ is the diameter of the retention chamber, $L_{r e t}$ is the length of the retention chamber $(\mathrm{m}), D_{\text {or }}$ is the diameter of the outlet orifice from the pipe chamber $(\mathrm{m}), D_{\text {in }}$ is the diameter of the inlet channel (m), $D_{\text {out }}$ is the diameter of the outlet chamber $(\mathrm{m}), h$ is the filling level of the retention chamber $(\mathrm{m}), i$ is the longitudinal slope of the pipe chamber (-), $U_{a v}$ is the average flow velocity of the stormwater in the retention chamber $\left(\mathrm{ms}^{-1}\right), I_{i n}$ is the stormwater discharge flowing into the tank $\left(\mathrm{m}^{3} \mathrm{~s}^{-1}\right), I_{\text {out }}$ is the stormwater discharge flowing out of the retention chamber $\left(\mathrm{m}^{3} \mathrm{~s}^{-1}\right), 1$ is the inlet channel, 2 is the inlet chamber, 3 is the retention chamber, 4 is the safety overflow, and 5 is the outlet chamber.

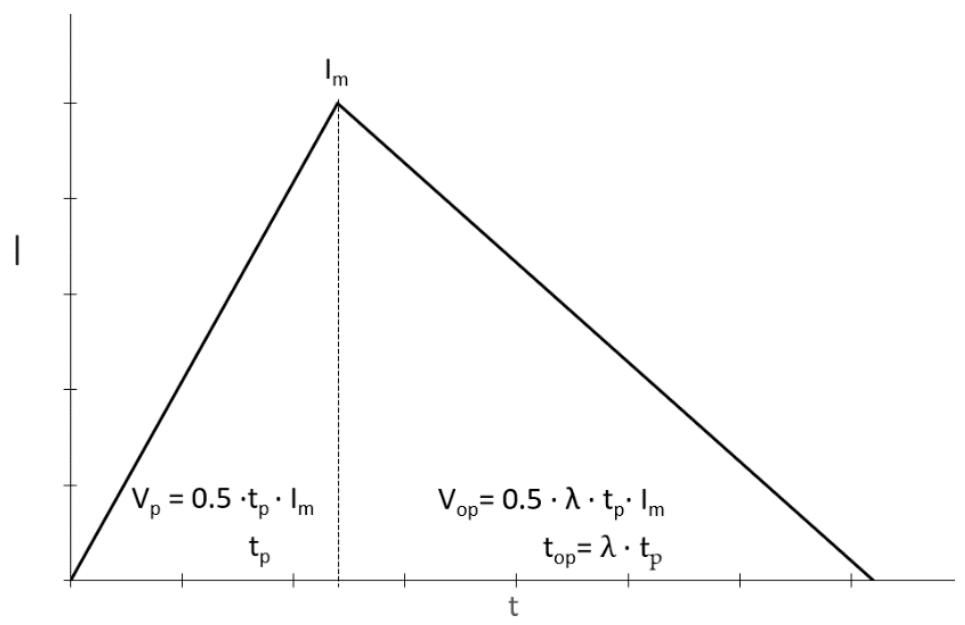

Figure 3. The inflow hydrograph adopted for calculating the storage tank volume.

\subsection{Dimensionless Differential Equation of Volume Balance}

In order to reduce the number of independent variables while designing the pipe tank, a normalization of the differential Equations (3) and (4) was performed in order to develop a simplified methodology. For this purpose, the following normalization variables were introduced:

- $\quad$ Dimensionless time from the start $\left(t^{*}\right)$ :

$$
t^{*}=\frac{t}{t_{p}}
$$

- $\quad$ Dimensionless flow rate $\left(I^{*}\right)$ :

$$
I^{*}=\frac{I(t)}{I(t)_{m}}
$$

- $\quad$ Dimensionless tank volume $\left(V^{*}\right)$ :

$$
V^{*}=\frac{V}{V_{c}}
$$


where $V_{c}$ is the total inflow hydrograph volume $\left(\mathrm{m}^{3}\right), V_{c}=I_{\max }\left(t_{p}+t_{o p}\right) / 2$.

By substituting Equations (5)-(7) into (3) and (4), the following dependences were obtained:

$$
\begin{gathered}
\frac{d V^{*}}{d t^{*}}=\omega \cdot t^{*}-\eta \cdot\left(V^{*}\right)^{0.35} \\
\frac{d V^{*}}{d t^{*}}=\omega \cdot\left(1+\frac{t_{p}}{t_{o p}}-t^{*}\right)-\eta \cdot\left(V^{*}\right)^{0.35}
\end{gathered}
$$

where: $\eta$ is the parameter combining the tank characteristics and the influent hydrograph, determined as [69]:

$$
\eta=\frac{B_{o r} \cdot t_{p}}{C_{z}^{0.35} \cdot V_{c}^{0.35}}=\frac{B_{o r} \cdot t_{p}}{\left(L_{r e t} \cdot D_{r e t}^{0.60}\right)^{0.35} \cdot V_{c}^{0.35}}
$$

where $\omega$ is the influent hydrograph shape parameter, calculated using the formula:

$$
\omega=\frac{I_{m} \cdot t_{p}}{V_{c}}
$$

The calculations of the required retention chamber length were conducted assuming the complete filling of pipe $D_{\text {ret }}$. When the retention chamber is completely filled, the maximal flow rate through the outlet orifice equals:

$$
I_{\text {out }, \text { max }}\left(h=D_{\text {ret }}\right)=B_{\text {or }} \cdot \sqrt{D_{\text {ret }}}
$$

Based on the data presented above, the coefficient of maximal flow reduction was determined:

$$
\beta=\frac{I_{\text {out }, \text { max }}\left(h=D_{\text {ret }}\right)}{I_{m}}=\frac{B_{o r} \cdot \sqrt{D_{\text {ret }}}}{I_{m}}
$$

The calculation of the retention tank volume was performed using the triangular influent hydrograph, with volume in the range of $V_{c}=900 \div 45,000 \mathrm{~m}^{3}$, a peak flow of $\left(I_{m}=1.5 \div 7.5 \mathrm{~m}^{3} \mathrm{~s}^{-1}\right)$, and peak flow time $t_{p}=10 \div 150 \mathrm{~min}$. For the assumed hydrographs, the obtained values of the $\omega$ parameter ranged from 0.15 to 1.00 . This assumption taken for the calculation actually meant that the peak time $t_{p}$ was assumed to be maximal at one-half of the end hydrograph time. That assumption was related to the fact that, to determine the nomogram with the widest possible range of parameters enabling all possible cases were taken into account, even the unlikely ones, to conditions of maximal tank capacity. The length of the retention chamber was calculated assuming $\beta=0.1-0.9$ and the diameter of the outlet orifice $D_{\text {or }}=0.25 \div 1.25 \mathrm{~m}$. The differential equation $V_{(h)}=f_{(t)}$ was solved using the explicit Runge-Kutta method, in relation to retention chamber length $L_{r e t}$ [79].

\subsection{Local Sensitivity Analysis}

Sensitivity analysis constitutes an important tool for investigating mathematical models, because it enables us to determine the degree of change in the model response to changes in the input parameters, and thus to determine the strength of the relationship between uncertain inputs and the output. This is essential for reducing the number of variables with the least influence on the model response and putting in the effort to minimize the uncertainties of the inputs with the stronger relationships to the model response. One of the most commonly employed methods is local sensitivity analysis, which enables us to calculate the coefficient of sensitivity using the following formula [80]:

$$
S_{X_{i}}=\sigma_{X_{i}} \cdot \frac{\partial y}{\partial x_{i}}
$$

Dependence (14) is a function of variable $x_{i}$ which is the product of the standard deviation $\sigma_{X i}$ and the derivative of partial primary function $\partial y / \partial x_{i}$. The number of sensitivity 
functions that can be created for one primary function is equal to the number of variables (and parameters) in the primary function.

Since the above-mentioned information sought the areas of parameter variability for which the considered sensitivity functions $\left(S_{t p}, S_{I m}, S_{\lambda}, S_{\eta}\right.$, where ${ }_{\lambda}$ and $\eta$ are sensitivity coefficients) were highly sensitive, a local sensitivity analysis was employed to assess the influence of the influent hydrograph parameters $\left(t_{p}, I_{m}, \lambda=t_{o p} \cdot t_{p}{ }^{-1}\right)$ on the length of the retention chamber. The standard deviation $\left(\sigma_{X i}\right)$ of the aforementioned variables in the presented methodology was determined using the Monte Carlo method, by sampling 1000 values from continuous uniform distributions, where the independent variables changed within appropriately assumed ranges. In this case, the sensitivity function described with formula (14) illustrates the change to the retention chamber length in relation to the unit change of parameter $x_{i}$. On the basis of the above-mentioned dependencies (see Equation (10)), the relationship describing the length of the chamber was determined and, then, the successive partial derivatives were determined. The following sensitivity functions $(S)$ were developed, enabling us to evaluate the effect of the influent hydrograph parameters and $\eta$ on the length of the retention chamber:

$$
\begin{gathered}
S_{t_{p}}=\sigma_{t_{p}} \cdot \frac{\partial L_{r e t}}{\partial t_{p}}=\sigma_{t_{p}} \cdot\left(\frac{1.57 \cdot B_{o r}}{D_{r e t}^{0.21} \cdot \eta \cdot\left(I_{m} \cdot(\lambda+1)\right)^{0.65}}\right)^{2.86} \\
S_{I_{m}}=\sigma_{I_{m}} \cdot \frac{\partial L_{r e t}}{\partial I_{m}}=-1.86 \cdot \sigma_{I_{m}} \cdot\left(\frac{1.57 \cdot B_{o r} \cdot t_{p}^{0.35}}{D_{r e t}^{0.21} \cdot \eta \cdot I_{m} \cdot(\lambda+1)^{0.65}}\right)^{2.86} \\
S_{\lambda}=\sigma_{\lambda} \cdot \frac{\partial L_{r e t}}{\partial \lambda}=-1.86 \cdot \sigma_{\lambda} \cdot\left(\frac{1.57 \cdot B_{o r} \cdot t_{p}^{0.35}}{D_{r e t}^{0.21} \cdot \eta \cdot I_{m}^{0.65} \cdot(\lambda+1)}\right)^{2.86} \\
S_{\eta}=\sigma_{\eta} \cdot \frac{\partial L_{r e t}}{\partial \eta}=\frac{-2.86}{\eta^{3.86}} \cdot\left(\frac{1.57 \cdot B_{o r}}{D_{r e t}^{0.21} \cdot\left(I_{m} \cdot(\lambda+1)\right)^{0.65}}\right)^{2.86}
\end{gathered}
$$

On the basis of the dependences (15)-(18), the sensitivity functions were determined, which constituted the basis for ascertaining the relations $S_{I m}=f\left(I_{m}, \lambda\right), S_{t p}=f\left(t_{p}, \lambda\right), S_{\lambda}=f\left(t_{p}\right.$, $\lambda)$, and $S_{\eta}=f\left(t_{p}, \eta\right)$.

\subsection{Influence of Hydrograph Parameters and Outlet Devices on Calculation Errors}

In the presented methodology, in order to determine the effect of the approximation $\eta=f(\omega, \beta)[69]$ on the prediction error of the retention tank volume obtained from the performed numerical calculations, the relative errors were determined using the formula presented below:

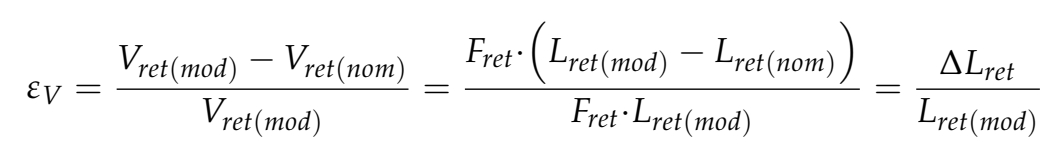

where: $V_{\text {ret }[\text { mod] }}$ is the tank volume obtained basing on numerical simulations $\left(\mathrm{m}^{3}\right), V_{\text {ret }[\text { nom }}$ is the tank volume determined based on the proposed nomograms $\left(\mathrm{m}^{3}\right), L_{\text {ret }[\text { mod] }}$ is the tank length calculated using the simulations $(\mathrm{m}), L_{\text {ret }[n o m]}$ is the tank length determined based on the proposed nomogram (see Figure 4$)(\mathrm{m}), F_{\text {ret }}$ is the transverse cross-section area of the retention chamber $\left(\mathrm{m}^{2}\right)$, and $\Delta L_{\text {ret }}$ is the absolute error of the predicted tank length.

The tank volume was obtained basing on the numerical simulations and the differential equations of the volume balance solved iteratively, the methodology for which was presented by Kiczko et al. [81]. 
In the present research, the absolute error of the predicted tank length was calculated using the following formula:

$$
\Delta L_{r e t}=\left(\frac{C_{o r} \cdot t_{p}}{D_{r e t}^{0.21} \cdot V_{c}^{0.65}}\right)^{2.857} \cdot\left(\frac{1}{\eta_{m o d}^{2.857}}-\frac{1}{(\alpha \cdot \omega)^{2.857}}\right)
$$

where: $\eta_{\text {mod }}$ is the the value of the parameter determined on the basis of a simulation using a hydrodynamic model, i.e., the results from SWMM were taken, and the $\eta$ was directly substituted and determined here based on data from the hydrograph, the diameter of the retention pipe chamber and the diameter of the outlet orifice from the pipe chamber. The range of parameter changed from 0.0328 to 0.7032 .

The storm water management model (SWMM) is a dynamic rainfall-runoff simulation model used for the single-event or long-term (continuous) simulation of runoff quantity and quality from primarily urban areas $[25,82,83]$. It contains a flexible set of hydraulic modeling capabilities used to route runoff and inflows through a network of drainage system pipes, channels, storage/treatment units, and diversion structures [84,85]. Flow routing within a conduit link in the SWMM is governed by the equations of mass and momentum conservation for gradually varied, unsteady flow. The user has a choice of three approaches for flow routing: steady flow, kinematic wave, and dynamic wave routing. Dynamic wave routing solves the complete set of one-dimensional Saint-Venant flow equations and therefore produces the most theoretically accurate results. These equations consist of continuity and momentum equations for conduits and a volume continuity equation for the nodes. The SWMM model can also simulate pressurized flow in the network. Because it couples together the solutions for both the water levels at the nodes and the flow in the conduits, the SWMM model can be applied to any general network layout, even those containing multiple downstream diversions and loops.

There is no available module for pipe tank dimensioning in the SWMM software. The tested pipe tank was modeled in SWMM as a pipe combined with inflow and outflow chambers (nodes) (Figure 2). Inflow from the tank was defined as the drain hole with an assumed diameter and outflow coefficient. The hydraulic conditions inside the retention chamber (time-related variability of filling and velocity of flow) were analyzed in the developed model. The dynamic wave equation was used to determine the tank parameters, with an assumed value of the routing step equal to $1 \mathrm{~s}$, while the reporting step of the result was selected as $2 \mathrm{~s}$. The Extended Transport (EXTRAN) Block was applied for the simulation of tank operation, while the Darcy-Weisbach model was selected to determine friction loss. The rainwater inflow in the developed SWMM model was assigned at the node (manhole) before the retention chamber. The length of the retention chamber was determined by the successive iterative approximations for the assumed hydrograph and length of the retention chamber and outflow devices, for which the tank filling time was calculated using the SWMM simulations. The conditions for the iterative process were to maintain pressureless flow conditions inside the pipe retention tank and to achieve the maximal water depth in the pipe tank as close as possible to the pipe tank diameter. When the calculated maximal filling of the retention chamber was lower than the diameter of the retention pipe, the length of the retention chamber was decreased until the calculated maximal filling height was equal to the diameter of the retention pipe [60].

\subsection{Modeling of the Errors in the Predicted Tank Length Using Data Mining Methods}

In the analyses, the errors in the simulations of retention chamber length performed using the simplified method were predicted with the multiple linear regression method, genetic programming (GP), and artificial neural network "multilayer perceptron" (MPL). Taking into account the lack of specific guidelines relating to the selection of optimal network architecture for identifying the best neural networks, the STATISTICA automated neural network option was used in the present work [86]. In the performed studies, the linear, hyperbolic sinus, hyperbolic tangent, exponential, and logistic active functions were 
considered in the neurons of the hidden and output layers. In order to correctly conduct the learning process and then evaluate the operation, the theoretical values of the retention chamber length prediction errors were divided into three sets (training- $50 \%$, validation$25 \%$, and test-25\%). The training of the neural network was performed with the BroydenFletcher-Goldfarb-Shanno method [74]. One hundred artificial neural networks were generated in order to select the best artificial neural network (ANN) structure for the $\varepsilon$ error prediction.

\section{Results and Discussion}

\subsection{Dependence $\eta=f(\omega, \beta)$}

On the basis of the performed calculations, a nomogram (Figure 4) illustrating the influence of waveform $(\omega)$ on the parameter $\eta$ for constant values of the peak flow reduction coefficient $(\beta=0.1 \div 0.9)$ was developed. While analyzing the variability of the obtained curves, it was indicated that the dependence $\eta=f(\omega, \beta=$ const $)$ was linear:

$$
\eta=\mu \cdot \omega+\gamma
$$

where: $\mu, \gamma$ are the empirical parameters characteristic for each value of the peak flow reduction coefficient, determined using the maximum likelihood estimation method.

On the basis of the calculations, it was observed that by extrapolating the variability $\eta=f(\omega, \beta=$ const $)$ with a linear function, the values of the determination coefficient $\left(r^{2}\right)$ in Equation (22) ranged from 0.989 to 0.996 for $\beta=0.1 \div 0.9$. The determined curves showed that the values of $\eta$ increased along with $\beta$. The $\eta=f(\omega, \beta=$ const $)$ curves determined in the form of the nomogram indicated that the greater the value of peak flow reduction and influent hydrograph asymmetry coefficients, the higher the increase in the dispersion of the $\eta$ parameter values for the analyzed wave asymmetry coefficient $(\omega=0.2 \div 1.0)$, and thus the higher the prediction error of the tank volume.

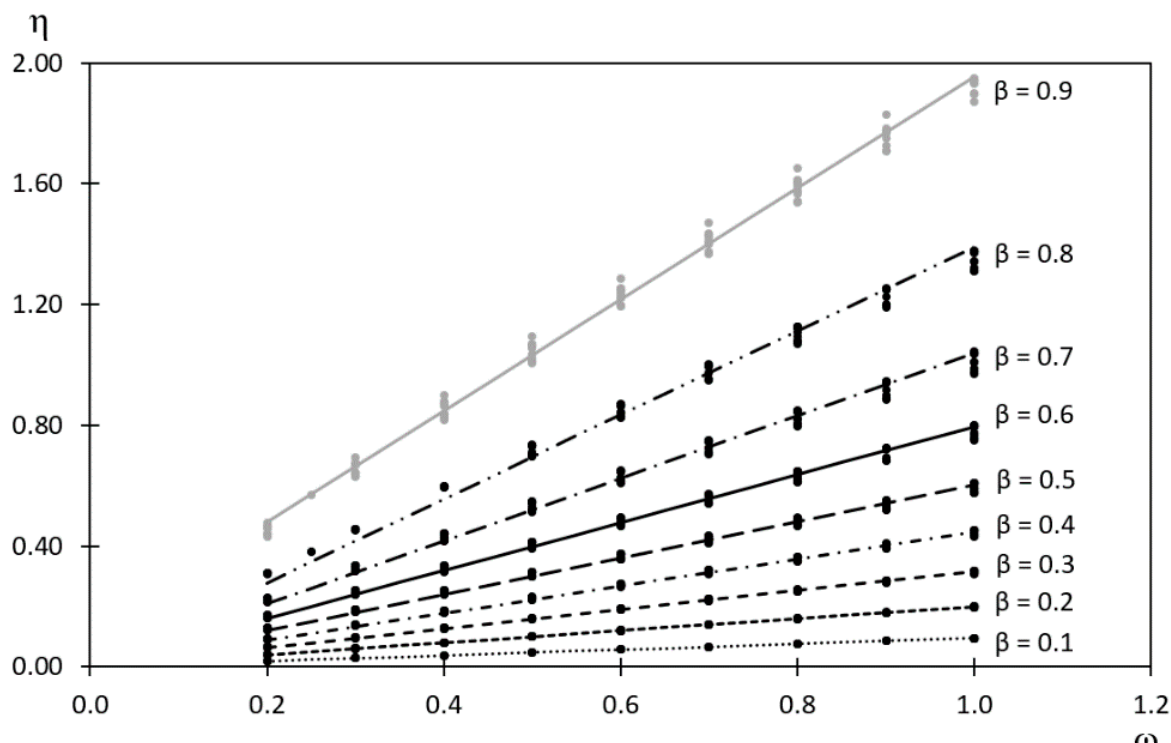

Figure 4. Influence of the $\eta$ parameter and wave asymmetry coefficients $(\omega)$ on the peak flow reduction coefficient $(\beta)$. Points correspond to the values acquired from simulations, whereas curves are related to the values obtained by means of Formula (21).

On the basis of the performed calculations (Figure 5a) it was observed that an increase in peak flow led to a decrease in the sensitivity coefficient $S_{I m}=f\left(I_{m}, \lambda\right)$ in the analyzed range. It should be noted that in the range $I_{m}=0.0 \div 3.0 \mathrm{~m}^{3} \mathrm{~s}^{-1}$, the $S_{I m}$ values for $t_{p}=500 \mathrm{~s}$ and $t_{p}=1500 \mathrm{~s}$ changed in the range from $-0.75 \times 10^{6}$ to $-0.25 \times 10^{6}$, and from $-2.5 \times 10^{6}$ to $-0.30 \times 10^{6}$, respectively. In turn, for $I_{m}>3.0 \mathrm{~m}^{3} \mathrm{~s}^{-1}$ the changes to $S_{I m}$ in the above- 
mentioned ranges did not exceed $10 \%$. The performed calculations (Figure $5 \mathrm{~b}$ ) indicate that the increase in time from $t_{p}=500 \mathrm{~s}$ to $t_{p}=2000 \mathrm{~s}$ for $I_{m}=2.0 \mathrm{~m}^{3} \mathrm{~s}^{-1}$ did not affect the value of the sensitivity index $S_{p}=f\left(t_{p}, \lambda\right)$, while a change to the peak flow at its maximum in the range from $I_{m}=2.0 \mathrm{~m}^{3} \mathrm{~s}^{-1}$ to $I_{m}=4.0 \mathrm{~m}^{3} \mathrm{~s}^{-1}$ reduced the sensitivity index $S_{t p}$ by $14 \times 10^{6}$ to $8 \times 10^{6}(43 \%)$.

Moreover, an increase in the peak flow in the analyzed time range of peak flow time $t_{p}=500 \div 2000 \mathrm{~s}$ (Figure 5 c) reduced the sensitivity index $S_{\lambda}=f\left(t_{p}, \lambda\right)$. Nevertheless, it should be noted that in the range of $I_{m}=0.0 \div 3.0 \mathrm{~m}^{3} \mathrm{~s}^{-1}$, the values of $S_{\lambda}$ for $t_{p}=500 \mathrm{~s}$ and $t_{p}=1500 \mathrm{~s}$ changed from -4200 to -600 and $-11,000$ to -600 , respectively, whereas for $I_{m}>3.0 \mathrm{~m}^{3} \mathrm{~s}^{-1}$, the change of $S_{\lambda}=f\left(t_{p}, \lambda\right)$ in the above-mentioned ranges did not exceed $10 \%$ and $14 \%$, respectively. The performed calculations (Figure $5 \mathrm{~d}$ ) indicated that, for $\eta \approx 0$ in the analyzed range $I_{\max }$, there was a sharp change in the sensitivity index $S_{\eta}$, whereas for $\eta>\eta_{g r}$, the values of the sensitivity index $S_{\eta}$ were constant and equaled $-0.3 \times 10^{9}$.

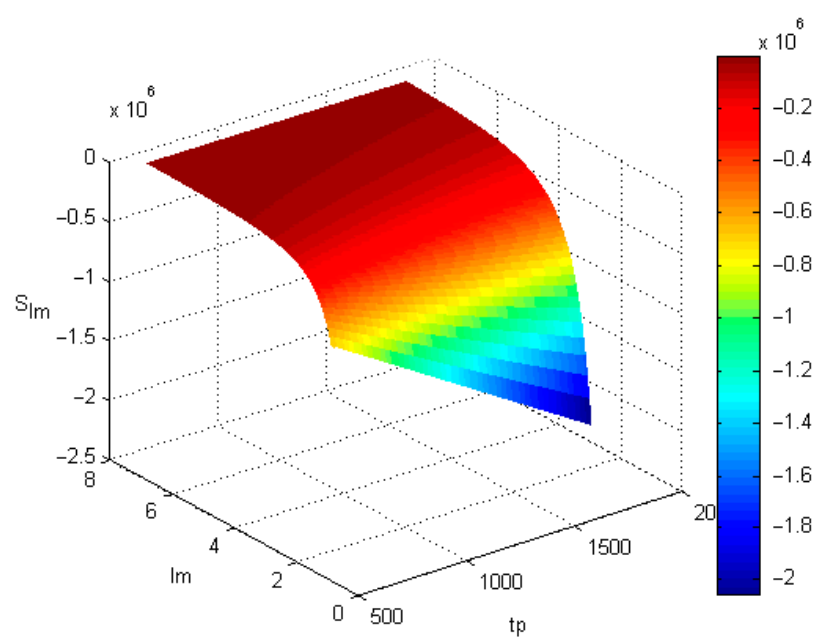

(a)

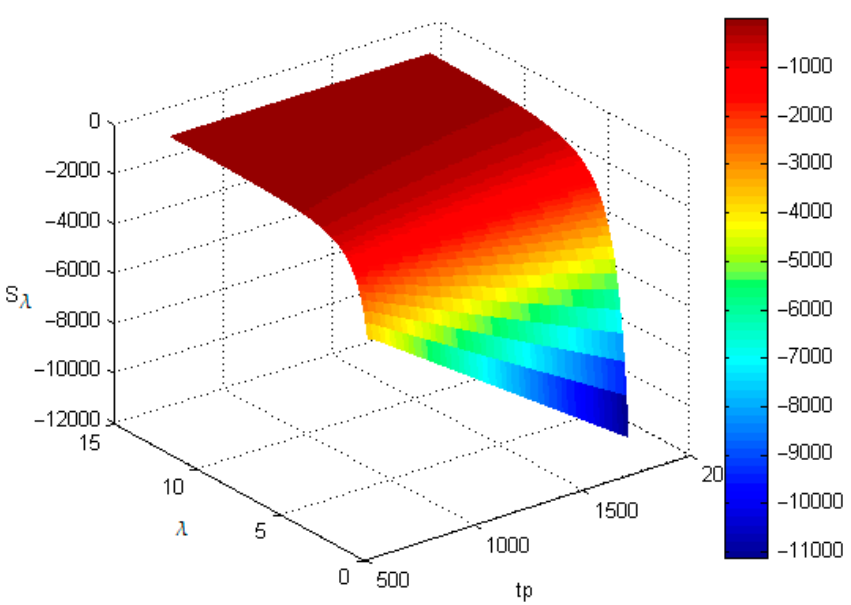

(c)

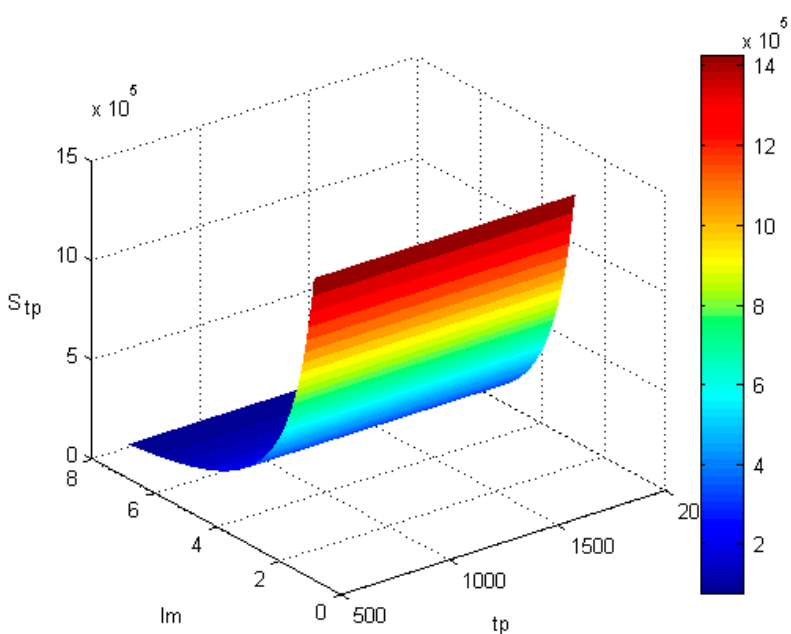

(b)

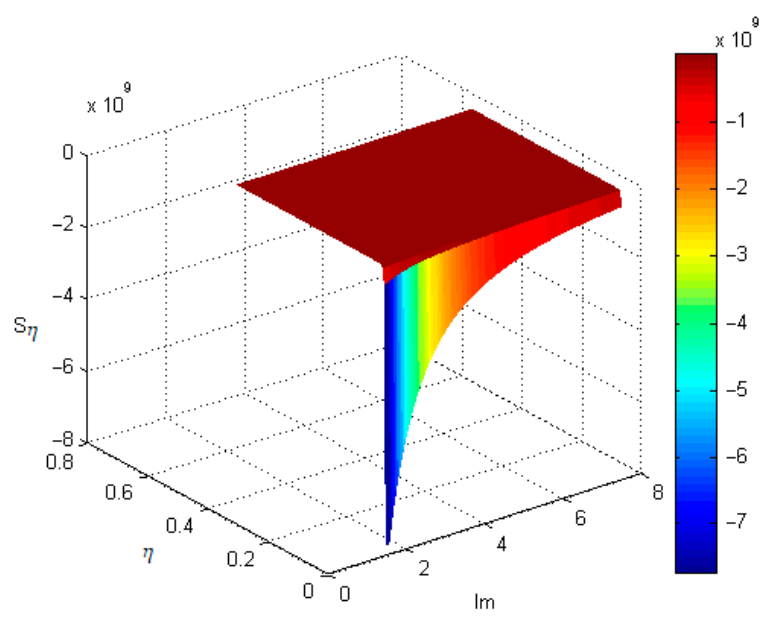

(d)

Figure 5. Variability of the sensitivity index (a) $S_{I m}=f\left(I_{\max }=I_{m}, t_{p}\right),(\mathbf{b}) S_{t p}=f\left(I_{\max }=I_{m}, t_{p}\right),(\mathbf{c}) S_{\lambda}=f\left(\lambda, t_{p}\right),(\mathbf{d}) S_{\eta}=f(\eta$, $\left.I_{\max }=I_{m}\right)$.

The results obtained from the calculations were confirmed by analyses performed by Paik [87], where the analytical relations allowing the determination of the tank volume were developed. Using the First Order Reliability Model (FORM) method, it was determined that among the analyzed characteristics of the hydrograph and device dimensions, both 
had a significant influence on the volume of the designed rainwater retention tank. Taking into account that the paper by Paik [87] considered open reservoirs, the influence of the hydrograph parameters $\left(I_{\max }, \lambda\right)$ on the reservoir area was not analyzed. In turn, the paper by Guo [66] presented an analytical-graphical method supported by several computational variants. This paper concerned two methodologies: a very precise one allowing errors lower than $2 \%$ and another, simplified one, for which the difference between the obtained results and the reference data was at the level of $4 \%$.

3.2. Influence of the Influent Hydrograph Parameters and Tank Characteristics on the Errors in the Prediction of Its Volume

On the basis of the developed nomogram $\eta=f(\omega, \beta)$ (Figure 4) and the performed numerical calculations, the values of the relative errors $\left(\varepsilon_{V}\right)$ committed using the developed graph were determined with Formula (22). Table 1 lists only the minimum and maximum values of $\varepsilon_{V}$.

Table 1. Maximum values of relative errors $\left(\varepsilon_{V \max }\right)$ for the peak flow reduction coefficients $\beta=0.1 \div 0.9$.

\begin{tabular}{cccccccccc}
\hline $\boldsymbol{\beta}$ & $\mathbf{0 . 1}$ & $\mathbf{0 . 2}$ & $\mathbf{0 . 3}$ & $\mathbf{0 . 4}$ & $\mathbf{0 . 5}$ & $\mathbf{0 . 6}$ & $\mathbf{0 . 7}$ & $\mathbf{0 . 8}$ & $\mathbf{0 . 9}$ \\
\hline$\varepsilon_{V \max }$ & 3.77 & 5.75 & 6.16 & 6.31 & 9.45 & 11.19 & 12.92 & 18.44 & 22.13 \\
$\varepsilon_{V \min }$ & -7.01 & -7.28 & -9.79 & -12.07 & -18.08 & -20.51 & -22.93 & -25.03 & -36.33 \\
\hline
\end{tabular}

The performed calculations (Table 1) indicate that while determining the tank volume using the developed nomogram $\eta=f(\omega, \beta)$, the lowest maximum relative error $\left(\varepsilon_{V \max }\right)$ was observed for $\beta=0.1$ and its extreme values ranged from $-7.01 \%$ to $3.77 \%$. On the contrary, the greatest error noted was for $\beta=0.9$ and varied from $-36.33 \%$ to $22.13 \%$. This means that the relative error values related to the tank volume prediction were significant, thus confirming the need for their estimation. In the performed work, $\varepsilon_{V}$ was first determined using the multiple stepwise regression method because the variables with negligible effect on the relative error of the retention chamber volume were omitted during the calculations. Thus, the following formula was obtained:

$\varepsilon_{V}=0.788( \pm 0.039) \cdot \eta+0.714( \pm 0.041) \cdot \omega+1.621( \pm 0.086) \cdot I_{m}+0.2( \pm 0.002) t_{p}-2.614( \pm 0.073) \cdot$

$$
D_{\text {or }}-0.852( \pm 0.079) \cdot D_{\text {ret }}
$$

Taking into account the results obtained pertaining to the creation of error prediction models based on artificial neural networks and genetic programming, the following variables (see Equation (22)) were used: the $\eta$ parameter, the coefficient of stormwater volume distribution unevenness in hydrograph $(\omega)$, peak flow to the tank $\left(I_{m}\right)$, the time of the peak flow $\left(t_{p}\right)$, the diameter of the outlet device $\left(D_{o r}\right)$, and the diameter of the retention chamber $\left(D_{r e t}\right)$. The parameters of the proposed mathematical models are presented in Table 2, while Figures 6 and 7 show a comparison of the $\varepsilon_{v}$ values, both calculated and determined on the basis of the numerical simulations and the developed nomogram $\eta=f(\omega, \beta)$. The performed calculations (Table 2) indicated a comparable agreement of the calculations and measurements of the relative errors $\left(\varepsilon_{V}\right)$ obtained by the means of an artificial neural network with 6 neurons in the hidden and exponential activation functions, and using genetic programming. This was confirmed by the values of the particular fitting parameters (Table 2) since in the case of multiple regressions, ANN, and GP $(\omega, \beta)$, the correlation coefficient and Akaike information criterion amounted to 0.6851 and $-3553 ; 0.9310$ and -3010 as well as 0.9010 and -3236 , respectively. 
Table 2. Fitting measures of the obtained models predicting the relative error of tank volume $\left(\varepsilon_{\mathrm{V}}\right)$.

\begin{tabular}{ccccc}
\hline Method & RRE & MPE & r & AIC \\
\hline Regression & 0.0442 & 47.51 & 0.6851 & -3553 \\
ANN & 0.0272 & 5.60 & 0.9310 & -3010 \\
GP $(\omega, \eta)$ & 0.0345 & 8.02 & 0.8872 & -3321 \\
GP $(\omega, \beta)$ & 0.0312 & 7.89 & 0.8953 & -3299 \\
GP $(\omega, \beta)$ & 0.0296 & 7.21 & 0.9010 & -3236 \\
\hline
\end{tabular}

Where: REE: relative residual error, MPE: mean percentage error, r: correlation coefficient, AIC: Akaike information criterion.

It should be emphasized that the differences in the fitting parameters of the obtained models to the theoretical data in the cases of ANN and GP were insignificant, and the correlation coefficient was only $3 \%$ greater, while the mean error was $1.61 \%$ lower. Moreover, it should be noted that in the above-mentioned considerations, the result obtained using genetic programming constituted of the following deterministic dependences for indicating the relative error of volume prediction:

$$
\begin{array}{ll}
\varepsilon_{V}=0.2036 \cdot \eta \cdot(1-\omega) \cdot\left(\omega^{-1}-\eta\right) & (\mathrm{r}=0.8872) \\
\varepsilon_{V}=(\omega \cdot \beta)^{2} \cdot \sin (0.105)+0.2570 \cdot \beta^{2} \cdot \ln (\omega) & (\mathrm{r}=0.8953) \\
\varepsilon_{V}=0.1050 \cdot(\omega-0.7917) \cdot \ln (0.625 \cdot \omega)-0.376 \cdot \beta & (\mathrm{r}=0.9010)
\end{array}
$$

which were determined on the basis of the obtained parsing tree structures (Figures 6 and 7).
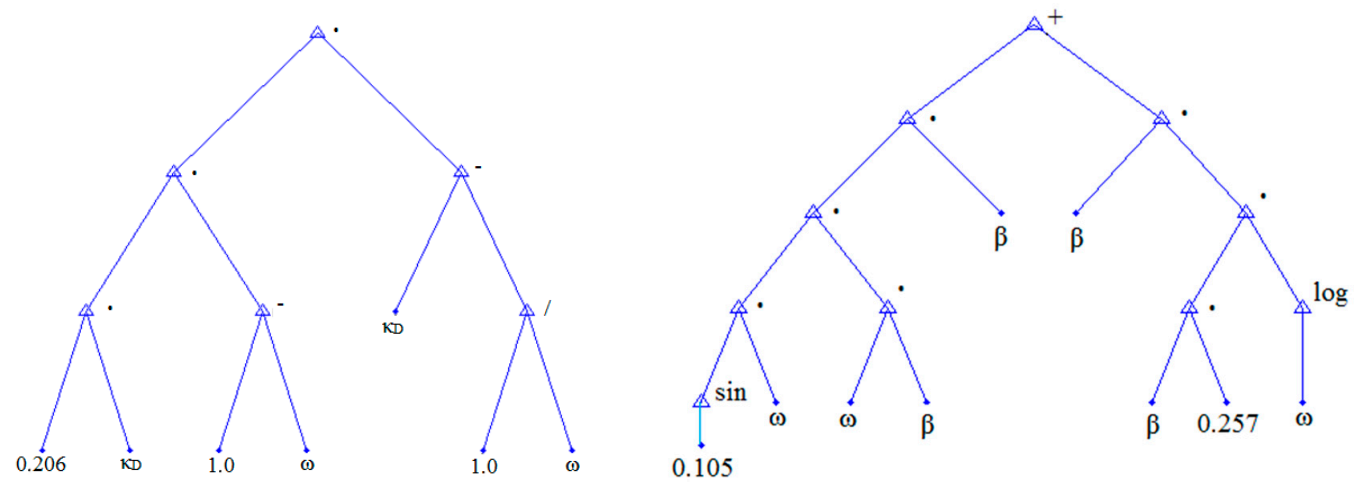

Figure 6. Structures of parsing trees for calculating $\varepsilon_{V}=(\omega, \eta, \beta)$.

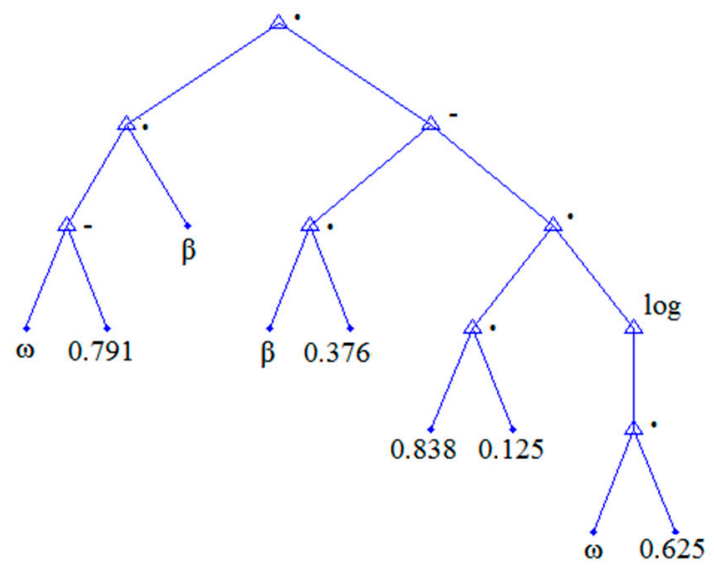

Figure 7. Structure of the parsing tree for calculating $\varepsilon_{V}=(\omega, \beta)$. 


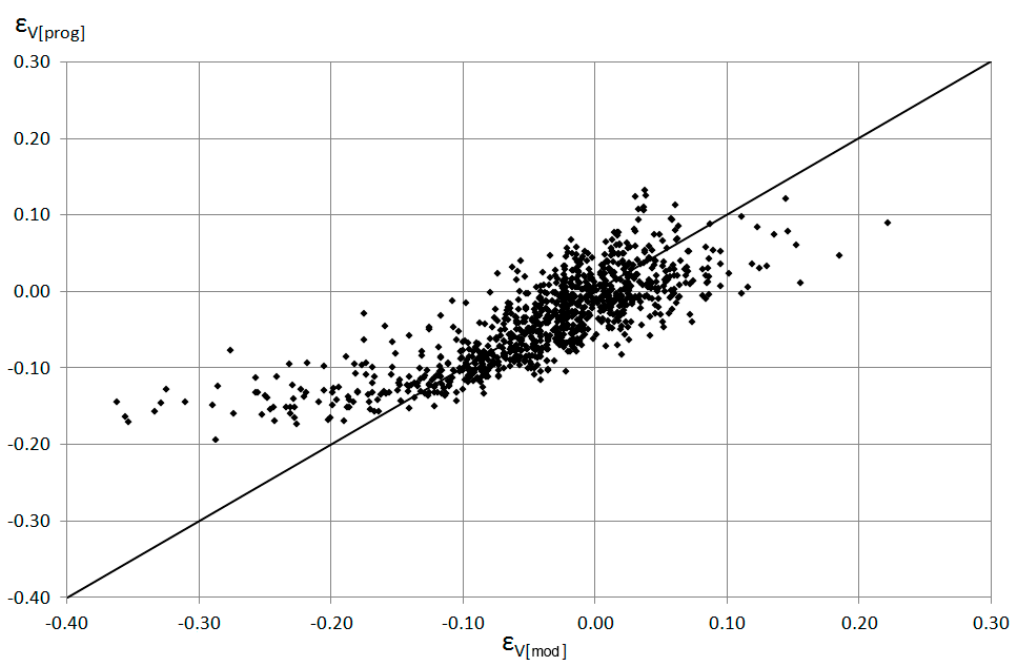

Figure 8. Comparison of the error values obtained on the basis of the developed nomogram $\varepsilon_{V[m o d]}$, calculated using multiple regression $\varepsilon_{V \text { [prog] }}$.

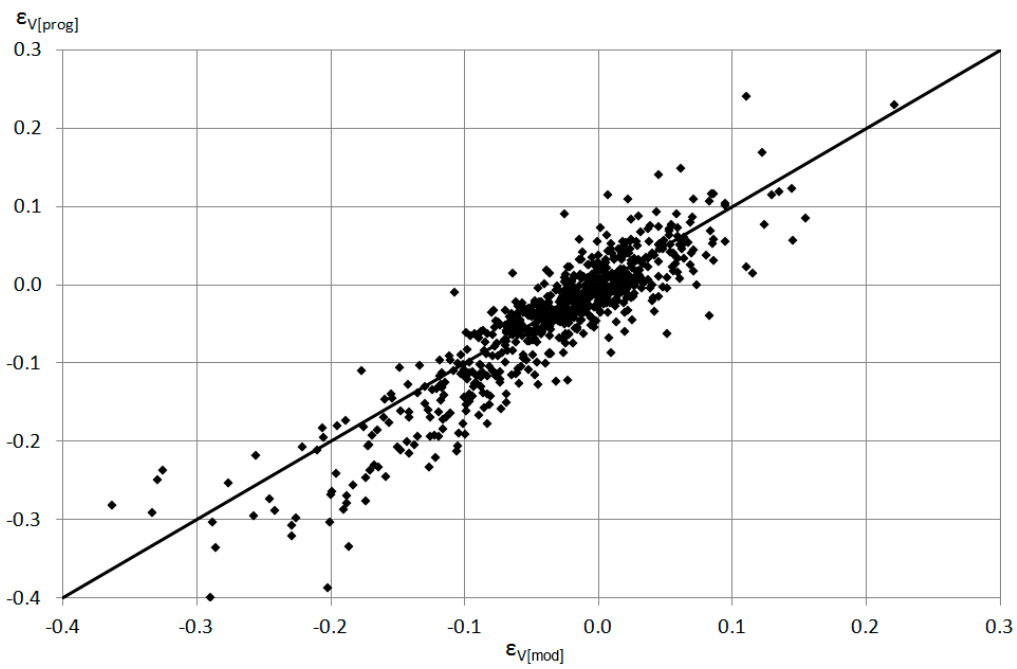

Figure 9. Comparison of the error values obtained on the basis of the developed nomogram $\varepsilon_{V[m o d]}$, calculated using genetic programming $\varepsilon_{V \text { [prog] }}$.

On the basis of Figures 8-10, it was observed that artificial neural networks were superior in predicting both the relative error values of the multiple regressions and the regression dependence obtained using the calculations performed with genetic programming for $\varepsilon_{V[\text { mod }]}<-0.10$.

The following case may be presented, as the exemplary calculations involving the developed method of pipe tank design:

$I_{\max }=3.34 \mathrm{~m}^{3} / \mathrm{s} t=15 \mathrm{~min}$ and $V=15,000 \mathrm{~m}^{3}$ i.e., $\omega=3.34 \times 15 \times 60 / 15,000=0.20$ (according Equation (11)).

$\beta=0.57 \times 3.14 / 4 \times\left(0.3^{2}\right) \times(19.62 \times 3.5)^{0.5}=0.10$ (according Equation (13)).

For $\omega=0.2$ and $\beta=0.1$, the value of $\eta=0.04$ (according Figure 4).

$C_{o r}=0.57 \times 0.785 \times 0.3^{2} \times\left(19.62^{0.5}\right)=0.313$ (according Equation (13)).

$L_{\text {ret }}=\left[0.313 \times 15 \times 60 /\left(3.5^{0.21} \times 15,000^{0.65} \times 0.04\right)\right]^{2.857}=815.3 \mathrm{~m}$ (according Equation $\left.(10)\right)$.

Applying the determined-model ANN for $\omega=0.2$ and $\beta=0.1$, the value $d L_{\text {ret }}=0.011$ was obtained, which gave a final result of $L_{\text {ret }}=823.5 \mathrm{~m}$.

For the assumed parameters of the hydrograph, the value of $\omega$ was determined using Equation (11), while $\beta$ was calculated for the assumed complete filling of the retention pipe. Assuming the complete filling of the pipe and an outflow from the tank using a $0.3 \mathrm{~m}$ pipe 
which allowed $\beta=0.1$, a value of $\eta=0.04$ was obtained from the nomogram (Figure 4 ). The obtained calculation results confirm that for small $\beta$ values the $L_{\text {ret }}$ calculation error values are relatively small, and amount to $1.1 \%$.

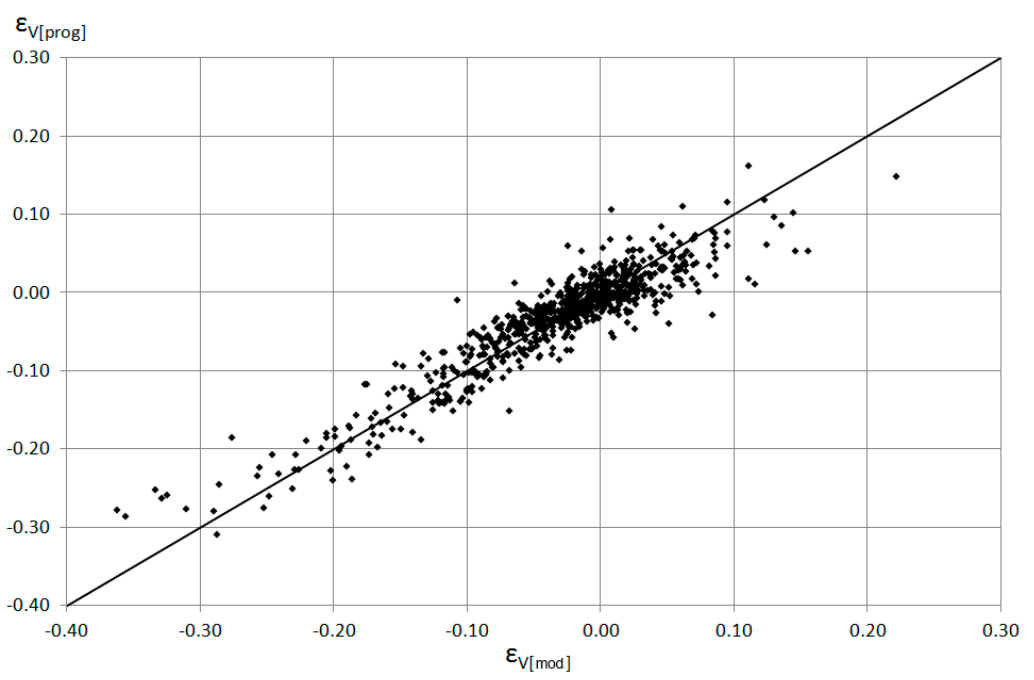

Figure 10. Comparison of the error values obtained on the basis of the developed nomogram $\varepsilon_{V[m o d]}$, calculated using ANN $\varepsilon_{V[p r o g]}$.

\section{Summary}

The results of the performed analysis confirm that the proposed integrated pipe tank design methodology can be used in engineering practice for the initial estimation of tank volume without the use of the correction module. Using the graphical and analytical methods, it is possible to pre-define the length of the tank chamber and to design the overflow devices. The additional implementation of data-mining methods allows us to detail the simulation results so that they are consistent with the results of the calculations of the length of the reservoir chamber obtained by means of differential equations. However, when designing the tank, special attention should be paid to the exact identification of the inflow hydrograph parameters to the tank, because they have a key impact on its dimensions.

The use of data mining methods in the calculation procedure led to improved error prediction results using the proposed pipe tank design method, as compared to the data obtained by the hydrodynamic model (SWMM).

The conducted analyses indicated that the flow reduction coefficient was an important factor affecting prediction errors related to the retention chamber length. It was indicated that the error increased with the coefficient value.

Reducing the tank length prediction error is significant from the viewpoint of optimizing the solutions applied to stormwater sewerage systems and runoff control, as well as the creation of hybrid systems consisting of sewer system retention and surface retention. This is significant in terms of obtaining the hydraulic retention effect, which is also important for improving the operational conditions of stormwater sewerage systems. This is essential in terms of making decisions on the modernization, reconstruction, or adoption of optimal variants of the stormwater sewerage system being designed.

Taking into account the usefulness to the engineering practice of the obtained results, the development of the proposed pipe tank dimensioning methodology and the possibility of its use for different hydrograph shapes are justified, despite the fact that the hydrograph shapes may differ from synthetic ones on real catchment runoff. 
Author Contributions: Conceptualization, B.S. and G.Ł.; methodology, data curation, software and visualization, B.S. and A.K.; formal analysis B.S., G.Ł., D.S. and M.S.; writing-original draft preparation, B.S., A.M.-P., M.K.W. and G.Ł.; writing-review and editing, B.S., A.K., A.M.-P., M.K.W., J.Z., G.Ł., D.S., M.S.; All authors have read and agreed to the published version of the manuscript.

Funding: Work was financially supported within the statutory research of particular scientific units under subvention for a science program.

Institutional Review Board Statement: Not applicable.

Informed Consent Statement: Not applicable.

Data Availability Statement: Not applicable.

Acknowledgments: The authors also want to thank the reviewers for their appreciation and the comments/suggestions made to the manuscript.

Conflicts of Interest: The authors declare no conflict of interest.

\section{References}

1. Arfanuzzaman, M.; Atiq Rahman, A. Sustainable water demand management in the face of rapid urbanization and ground water depletion for social-ecological resilience building. Glob. Ecol. Conserv. 2017, 10, 9-22. [CrossRef]

2. Nagypál, V.; Mikó, E.; Hodúr, C. Sustainable Water Use Considering Three Hungarian Dairy Farms. Sustainability 2020, $12,3145$. [CrossRef]

3. Özerol, G.; Dolman, N.; Bormann, H.; Bressers, H.; Lulofs, K.; Böge, M. Urban water management and climate change adaptation: A self-assessment study by seven midsize cities in the North Sea Region. Sustain. Cities Soc. 2020, 55, 102066. [CrossRef]

4. Kärrman, E. Strategies towards sustainable wastewater management. Urban. Water 2001, 3, 63-72. [CrossRef]

5. Garrick, D.; Iseman, T.; Gilson, G.; Brozovic, N.; O’Donnell, E.; Matthews, N.; Miralles-Wilhelm, F.; Wight, C.; Young, W. Scalable solutions to freshwater scarcity: Advancing theories of change to incentivise sustainable water use. Water Secur. 2020, 9, 100055. [CrossRef]

6. Willuweit, L.; O'Sullivan, J.J. A decision support tool for sustainable planning of urban water systems: Presenting the Dynamic Urban Water Simulation Model. Water Res. 2013, 47, 7206-7220. [CrossRef]

7. Paithankar, D.N.; Taji, S.G. Investigating the hydrological performance of green roofs using storm water management model. Mater. Today Proc. 2020, 32, 943-950. [CrossRef]

8. Simon, D. Our Common Future: Report of the World Commission on Environment and Development (Book Review). Third World Plan. Rev. 1987, 9, 285. [CrossRef]

9. Demuzere, M.; Orru, K.; Heidrich, O.; Olazabal, E.; Geneletti, D.; Orru, H.; Bhave, A.G.; Mittal, N.; Feliu, E.; Faehnle, M. Mitigating and adapting to climate change: Multi-functional and multi-scale assessment of green urban infrastructure. J. Environ. Manag. 2014, 146, 107-115. [CrossRef]

10. La Rosa, D.; Pappalardo, V. Planning for spatial equity - A performance based approach for sustainable urban drainage systems. Sustain. Cities Soc. 2020, 53, 101885. [CrossRef]

11. Wakode, H.B.; Baier, K.; Jha, R.; Azzam, R. Impact of urbanization on groundwater recharge and urban water balance for the city of Hyderabad, India. Int. Soil Water Conserv. Res. 2018, 6, 51-62. [CrossRef]

12. Tapia Silva, F.O.; Wehrmann, A.; Henze, H.-J.; Model, N. Ability of plant-based surface technology to improve urban water cycle and mesoclimate. Urban. For. Urban. Green. 2006, 4, 145-158. [CrossRef]

13. Paul, M.J.; Meyer, J.L. Streams in the Urban Landscape. Annu. Rev. Ecol. Syst. 2001, 32, 333-365. [CrossRef]

14. Mielby, S.; Eriksson, I.; Campbell, D.; De Beer, H.; Bonsor, H.; Le Guern, C.; van der Krogt, R.; Lawrence, D.; Ryzynski, G.; Schokker, J. Opening up the Subsurface for the Cities of Tomorrow. Considering the Access to Subsurface KnowledgeEvaluation of Practices and Techniques; COST Action TU1206 Sub-Urban Report; TU1206-WG2-001; TNO Publications; 2016, p. 119. Available online: http:/ / sub-urban.squarespace.com/s/TU1206-WG2-001-Opening-up-the-subsurface-for-the-cities-oftomorrow_Summary-Report.pdf (accessed on 13 September 2020).

15. Timm, A.; Kluge, B.; Wessolek, G. Hydrological balance of paved surfaces in moist mid-latitude climate-A review. Landsc. Urban. Plan. 2018, 175, 80-91. [CrossRef]

16. Wang, S.; Wang, H. Extending the Rational Method for assessing and developing sustainable urban drainage systems. Water Res. 2018, 144, 112-125. [CrossRef]

17. Cheng, M.-S.; Coffman, L.S.; Clar, M.L. Low-Impact Development Hydrologic Analysis. In Urban Drainage Modeling, Proceedings of the Specialty Symposium of the World Water and Environmental Resources Congress, Orlando, FL, USA, 20-24 May 2001; American Society of Civil Engineers: Reston, VA, USA, 2001; pp. 659-681.

18. Dietz, M.E. Low Impact Development Practices: A Review of Current Research and Recommendations for Future Directions. Water Air Soil Pollut. 2007, 186, 351-363. [CrossRef]

19. Ahiablame, L.M.; Engel, B.A.; Chaubey, I. Effectiveness of Low Impact Development Practices: Literature Review and Suggestions for Future Research. Water Air Soil Pollut. 2012, 223, 4253-4273. [CrossRef] 
20. Kaykhosravi, S.; Khan, U.; Jadidi, A. A Comprehensive Review of Low Impact Development Models for Research, Conceptual, Preliminary and Detailed Design Applications. Water 2018, 10, 1541. [CrossRef]

21. Khan, U.; Valeo, C.; Chu, A.; He, J. A Data Driven Approach to Bioretention Cell Performance: Prediction and Design. Water 2013, 5, 13-28. [CrossRef]

22. Elliott, A.; Trowsdale, S. A review of models for low impact urban stormwater drainage. Environ. Model. Softw. 2007, 22, 394-405. [CrossRef]

23. Fletcher, T.D.; Shuster, W.; Hunt, W.F.; Ashley, R.; Butler, D.; Arthur, S.; Trowsdale, S.; Barraud, S.; Semadeni-Davies, A.; BertrandKrajewski, J.-L.; et al. SUDS, LID, BMPs, WSUD and more-The evolution and application of terminology surrounding urban drainage. Urban. Water J. 2015, 12, 525-542. [CrossRef]

24. Ishaq, S.; Hewage, K.; Farooq, S.; Sadiq, R. State of provincial regulations and guidelines to promote low impact development (LID) alternatives across Canada: Content analysis and comparative assessment. J. Environ. Manag. 2019, 235, 389-402. [CrossRef] [PubMed]

25. Ghodsi, S.H.; Zahmatkesh, Z.; Goharian, E.; Kerachian, R.; Zhu, Z. Optimal design of low impact development practices in response to climate change. J. Hydrol. 2020, 580, 124266. [CrossRef]

26. Gaffin, S.; Khanbilvardi, R.; Rosenzweig, C. Development of a Green Roof Environmental Monitoring and Meteorological Network in New York City. Sensors 2009, 9, 2647-2660. [CrossRef] [PubMed]

27. Abdollahian, S.; Kazemi, H.; Rockaway, T.; Gullapalli, V. Stormwater Quality Benefits of Permeable Pavement Systems with Deep Aggregate Layers. Environments 2018, 5, 68. [CrossRef]

28. Šijanec Zavrl, M.; Tanac Zeren, M. Sustainability of Urban Infrastructures. Sustainability 2010, 2, 2950-2964. [CrossRef]

29. Sartipi, M.; Sartipi, F. Stormwater retention using pervious concrete pavement: Great Western Sydney case study. Case Stud. Constr. Mater. 2019, 11, e00274. [CrossRef]

30. Boogaard, F.; Lucke, T. Long-Term Infiltration Performance Evaluation of Dutch Permeable Pavements Using the Full-Scale Infiltration Method. Water 2019, 11,320. [CrossRef]

31. Saadeh, S.; Ralla, A.; Al-Zubi, Y.; Wu, R.; Harvey, J. Application of fully permeable pavements as a sustainable approach for mitigation of stormwater runoff. Int. J. Transp. Sci. Technol. 2019, 8, 338-350. [CrossRef]

32. Zhu, H.; Yu, M.; Zhu, J.; Lu, H.; Cao, R. Simulation study on effect of permeable pavement on reducing flood risk of urban runoff. Int. J. Transp. Sci. Technol. 2019, 8, 373-382. [CrossRef]

33. Nordbo, A.; Järvi, L.; Haapanala, S.; Wood, C.R.; Vesala, T. Fraction of natural area as main predictor of net CO 2 emissions from cities. Geophys. Res. Lett. 2012, 39, 2012GL053087. [CrossRef]

34. Morakinyo, T.E.; Lam, Y.F.; Hao, S. Evaluating the role of green infrastructures on near-road pollutant dispersion and removal: Modelling and measurement. J. Environ. Manage. 2016, 182, 595-605. [CrossRef] [PubMed]

35. Capotorti, G.; Alós Ortí, M.M.; Copiz, R.; Fusaro, L.; Mollo, B.; Salvatori, E.; Zavattero, L. Biodiversity and ecosystem services in urban green infrastructure planning: A case study from the metropolitan area of Rome (Italy). Urban. For. Urban. Green. 2019, 37, 87-96. [CrossRef]

36. Bressy, A.; Gromaire, M.-C.; Lorgeoux, C.; Saad, M.; Leroy, F.; Chebbo, G. Efficiency of source control systems for reducing runoff pollutant loads: Feedback on experimental catchments within Paris conurbation. Water Res. 2014, 57, 234-246. [CrossRef]

37. Palermo, S.A.; Talarico, V.C.; Turco, M. On the LID systems effectiveness for urban stormwater management: Case study in Southern Italy. IOP Conf. Ser. Earth Environ. Sci. 2020, 410, 012012. [CrossRef]

38. Dabas, R.; Kumar, S.; Kumar, M. Applications of Low Impact Development for Managing the Storm Water Surface Runoff in Urban Areas; Springer: Singapore, 2021; pp. 275-283.

39. Kevern, J.T. Green Building and Sustainable Infrastructure: Sustainability Education for Civil Engineers. J. Prof. Issues Eng. Educ. Pract. 2011, 137, 107-112. [CrossRef]

40. Winz, I.; Brierley, G.; Trowsdale, S. Dominant perspectives and the shape of urban stormwater futures. Urban. Water, J. 2011, 8, 337-349. [CrossRef]

41. Russo, A.; Escobedo, F.J.; Cirella, G.T.; Zerbe, S. Edible green infrastructure: An approach and review of provisioning ecosystem services and disservices in urban environments. Agric. Ecosyst. Environ. 2017, 242, 53-66. [CrossRef]

42. Starzec, M.; Dziopak, J. A Case Study of the Retention Efficiency of a Traditional and Innovative Drainage System. Resources 2020, 9, 108. [CrossRef]

43. Piro, P.; Carbone, M.; Morimanno, F.; Palermo, S.A. Simple flowmeter device for LID systems: From laboratory procedure to full-scale implementation. Flow Meas. Instrum. 2019, 65, 240-249. [CrossRef]

44. Sepehri, M.; Malekinezhad, H.; Ilderomi, A.R.; Talebi, A.; Hosseini, S.Z. Studying the effect of rain water harvesting from roof surfaces on runoff and household consumption reduction. Sustain. Cities Soc. 2018, 43, 317-324. [CrossRef]

45. Soonthornnonda, P.; Christensen, E.R. Source apportionment of pollutants and flows of combined sewer wastewater. Water Res. 2008, 42, 1989-1998. [CrossRef]

46. Park, M.-H.; Swamikannu, X.; Stenstrom, M.K. Accuracy and precision of the volume-concentration method for urban stormwater modeling. Water Res. 2009, 43, 2773-2786. [CrossRef]

47. Oviedo-Ocaña, E.R.; Dominguez, I.; Ward, S.; Rivera-Sanchez, M.L.; Zaraza-Peña, J.M. Financial feasibility of end-user designed rainwater harvesting and greywater reuse systems for high water use households. Environ. Sci. Pollut. Res. 2018, 25, 19200-19216. [CrossRef] 
48. Burns, M.J.; Fletcher, T.D.; Duncan, H.P.; Hatt, B.E.; Ladson, A.R.; Walsh, C.J. The performance of rainwater tanks for stormwater retention and water supply at the household scale: An empirical study. Hydrol. Process. 2015, 29, 152-160. [CrossRef]

49. Xu, W.; Fletcher, T.; Duncan, H.; Bergmann, D.; Breman, J.; Burns, M. Improving the Multi-Objective Performance of Rainwater Harvesting Systems Using Real-Time Control Technology. Water 2018, 10, 147. [CrossRef]

50. Musz-Pomorska, A.; Widomski, M.K.; Gołębiowska, J. Financial Sustainability of Selected Rain Water Harvesting Systems for Single-Family House under Conditions of Eastern Poland. Sustainability 2020, 12, 4853. [CrossRef]

51. Suleiman, L.; Olofsson, B.; Saurí, D.; Palau-Rof, L. A breakthrough in urban rain-harvesting schemes through planning for urban greening: Case studies from Stockholm and Barcelona. Urban. For. Urban. Green. 2020, 51, 126678. [CrossRef]

52. Melville-Shreeve, P.; Ward, S.; Butler, D. Rainwater Harvesting Typologies for UK Houses: A Multi Criteria Analysis of System Configurations. Water 2016, 8, 129. [CrossRef]

53. Lazarova, V.; Hills, S.; Birks, R. Using recycled water for non-potable, urban uses: A review with particular reference to toilet flushing. Water Supply 2003, 3, 69-77. [CrossRef]

54. GhaffarianHoseini, A.; Tookey, J.; GhaffarianHoseini, A.; Yusoff, S.M.; Hassan, N.B. State of the art of rainwater harvesting systems towards promoting green built environments: A review. Desalin. Water Treat. 2015, 1-10. [CrossRef]

55. Oberascher, M.; Zischg, J.; Palermo, S.A.; Kinzel, C.; Rauch, W.; Sitzenfrei, R. Smart Rain Barrels: Advanced LID Management through Measurement and Control; Springer: Cham, Switzerland, 2019; pp. 777-782.

56. Palermo, S.A.; Talarico, V.C.; Pirouz, B. Optimizing Rainwater Harvesting Systems for Non-potable Water Uses and Surface Runoff Mitigation; Springer: Cham, Switzerland, 2020; pp. 570-582.

57. Taji, S.G.; Saraf, V.R.; Regulwar, D.G. Smart Rain Water Harvesting for Smart Cities, In Studies in Systems, Decision and Control.; Springer: Cham, Switzerland, 2021; Volume 308, pp. 91-116.

58. Campisano, A.; Creaco, E.; Modica, C. Application of Real-Time Control Techniques to Reduce Water Volume Discharges from Quality-Oriented CSO Devices. J. Environ. Eng. 2016, 142, 04015049. [CrossRef]

59. Akan, A.O.; Houghtalen, R.J. Urban Hydrology, Hydraulics, and Stormwater Quality: Engineering Applications and Computer Modeling; John Wiley \& Sons, Inc.: Hoboken, NJ, USA, 2003; ISBN 0471431583.

60. Mrowiec, M. The Effective Dimensioning and Dynamic Regulation Sewage Reservoirs; Wydawnictwo Politechniki Częstochowskiej: Częstochowa, Poland, 2009; ISBN 9788371934247.

61. De Paola, F.; De Martino, F. Stormwater Tank Performance: Design and Management Criteria for Capture Tanks Using a Continuous Simulation and a Semi-Probabilistic Analytical Approach. Water 2013, 5, 1699-1711. [CrossRef]

62. Starzec, M.; Dziopak, J.; Słyś, D.; Pochwat, K.; Kordana, S. Dimensioning of Required Volumes of Interconnected Detention Tanks Taking into Account the Direction and Speed of Rain Movement. Water 2018, 10, 1826. [CrossRef]

63. Szelagg, B.; Kiczko, A.; Dabek, L. Stormwater Reservoir Sizing in Respect of Uncertainty. Water 2019, 11, 321. [CrossRef]

64. Kisiel, A.; Kisiel, J.; Malmur, R.; Mrowiec, M. Retention tanks as key elements of modern drainage systems. Tech. J. Environ. 2008, 105, 41-63.

65. Mrowiec, M. A tubular tank for stormwater storage in the stormwater collection system. Gas. Water Sanit. Eng. 2002, 7, 236-239.

66. Guo, J.C.Y. Detention Storage Volume for Small Urban Catchments. J. Water Resour. Plan. Manag. 1999, 125, 380-382. [CrossRef]

67. Hong, Y.-M.; Yeh, N.; Chen, J.-Y. The simplified methods of evaluating detention storage volume for small catchment. Ecol. Eng. 2006, 26, 355-364. [CrossRef]

68. Hong, Y.-M. Graphical estimation of detention pond volume for rainfall of short duration. J. Hydro-environ. Res. 2008, 2, 109-117. [CrossRef]

69. Szelag, B.; Kiczko, A. The graphic method of sizing pipe reservoir for short, high-intensity rainfalls. Ann. Warsaw Univ. Life Sci. L. Reclam. 2014, 46, 221-232. [CrossRef]

70. Rutkowska, D.; Piliński, M.; Rutkowski, L. Neural Networks, Genetic Algorithms and Fuzzy Systems; Wydaw. Naukowe PWN: Warszawa; Łódź, Poland, 1997; ISBN 978-83-01-12304-8.

71. Koza, J.R. Genetic programming as a means for programming computers by natural selection. Stat. Comput. 1994, 4, 87-112. [CrossRef]

72. Szelag, B.; Barbusinski, K.; Studzinski, J. Activated sludge process modelling using selected machine learning techniques. Desalin. WATER Treat. 2018, 117, 78-87. [CrossRef]

73. Capodaglio, A. Sludge bulking analysis and forecasting: Application of system identification and artificial neural computing technologies. Water Res. 1991, 25, 1217-1224. [CrossRef]

74. Rutkowski, L. Arificial Intellignce Methods and Techniques; Wydawnictwo Naukowe PWN: Warszawa, Poland, 2006.

75. Szelag, B.; Mrowiec, M. The methods of evaluating storage volume for single-chamber reservoir in urban catchments. Arch. Environ. Prot. 2016, 42, 20-25. [CrossRef]

76. Froehlich, D.C. Graphical Sizing of Small Single-Outlet Detention Basins in the Semiarid Southwest. J. Irrig. Drain. Eng. 2009, 135, 779-790. [CrossRef]

77. Guo, J.C.Y. Hydrology-Based Approach to Storm Water Detention Basin Design Using New Routing Schemes. J. Hydrol. Eng. 2004, 9, 333-336. [CrossRef]

78. McEnroe, B.M. Preliminary Sizing of Detention Reservoirs to Reduce Peak Discharges. J. Hydraul. Eng. 1992, 118, 1540-1549. [CrossRef] 
79. Starzec, M.; Dziopak, J.; Słyś, D. An Analysis of Stormwater Management Variants in Urban Catchments. Resources 2020, 9, 19. [CrossRef]

80. Pianosi, F.; Beven, K.; Freer, J.; Hall, J.W.; Rougier, J.; Stephenson, D.B.; Wagener, T. Sensitivity analysis of environmental models: A systematic review with practical workflow. Environ. Model. Softw. 2016, 79, 214-232. [CrossRef]

81. Kiczko, A.; Szelag, B.; Kozioł, A.P.; Krukowski, M.; Kubrak, E.; Kubrak, J.; Romanowicz, R.J. Optimal Capacity of a Stormwater Reservoir for Flood Peak Reduction. J. Hydrol. Eng. 2018, 23, 4018008. [CrossRef]

82. Rossman, L.A. Storm Water Management Model. User's Manual Version 5.1; National Risk Management Research Laboratory Office of Research and Development, U.S. Environmental Protection Agency: Cincinnati, OH, USA, 2015; Volume 352.

83. Zhang, S.; Guo, Y. SWMM Simulation of the Storm Water Volume Control Performance of Permeable Pavement Systems. J. Hydrol. Eng. 2015, 20, 06014010. [CrossRef]

84. El-Sharif, A.; Hansen, D. Application of SWMM to the Flooding Problem in Truro, Nova Scotia. Can. Water Resour. J. 2001, 26, 439-459. [CrossRef]

85. Sañudo, E.; Cea, L.; Puertas, J. Modelling Pluvial Flooding in Urban Areas Coupling the Models Iber and SWMM. Water 2020, 12, 2647. [CrossRef]

86. TIBCO Software Inc. Statistica (Automated Neural Network); Version 10; TIBCO Software Inc.: Palo Alto, CA, USA, 2011.

87. Paik, K. Analytical derivation of reservoir routing and hydrological risk evaluation of detention basins. J. Hydrol. 2008, 352, 191-201. [CrossRef] 